\title{
Exploration about the Reading Promotion Strategies in College Libraries-Taking the Huazhong University of Science and Technology Library as an Example
}

\author{
Lingling Peng \\ Huazhong University of Science and Technology Library \\ Wuhan, Hubei, China \\ E-mail: 85770286@qq.com
}

\author{
Chi Zhang* \\ Huazhong University of Science and Technology Library \\ Wuhan, Hubei, China \\ E-mail: 5788484@qq.com
}

\begin{abstract}
Currently, various college libraries have made lots of attempts concerning the reading promotion, Which is known as one of the important tasks for libraries. This paper introduces the practice that the Huazhong University of Science and Technology Library has made with regard to reading promotion from five aspects, including creating reading promotion, promoting the service of "the library paying for the new books selected by readers", carrying out subject librarian book review activities, adhering to holiday reading promotion, making a full play of the promotion function of reading club, so as to share the experience of our reading promotion with others, and explore more effective reading promotion methods.
\end{abstract}

Keywords—Reading promotion; College libraries; Strategies

\section{INTRODUCTION}

The promotion of nationwide reading activities is an important approach for constructing urban humanistic spirits, and is also the core contents for the construction of national culture. In the recent 10 years, China has advocated carrying out nationwide reading activities, and China Society for Library Science also established Science Popularization and Reading Guidance Committee in 2005, and then it was renamed as "Reading Promotion Committee" in 2009, and the function of libraries in reading promotion was increasingly highlighted. College libraries are important components for teaching and scientific research work of schools, and can bear compelling obligations in reading promotion. Currently, all college libraries have made lots of attempts considering the theme of reading promotion, and there are also many references discussing about the reading promotion from various aspects, such as the Existing Problems and Countermeasures about the Reading Promotion of College Libraries [1], and the Reading Promotion Evaluation Mechanism of College Libraries [2]. More references have shared about the reading promotion achievements of college libraries, such as the "Vertical Reading" Promotion of the Library of Tongji University [3], and the reading promotion of libraries under the new environment [4]. This paper introduces some explorations of the Huazhong University of Science and Technology Library considering reading promotion.

\section{READING PROMOTION STRATEGIES}

\section{A. Create reading promotion brand}

Reading promotion is not something that will be completed within a day or two or a year or two, it should become a continuous and persistent business of libraries. In order to truly respond to the call of Prime Minister Li Keqiang about "nationwide reading", and truly make reading a habit, our library released "a good book, accompanying you along the way" World Reading Day series of activities in 2015, and since then, "a good book, accompanying you along the way" reading promotion brand has been continued, especially on the annual World Reading Day, various series of activities were released, mainly including interaction activities, awarded work collection, films and television broadcasting, cultural lecture and other modules.

Interaction activities. On the annual World Reading Day, the library will release various forms of reader interaction activities, such as "Guessing the Book Name as per the Abstract", "Searching the Book for Treasures", "Gift for Entrance", "Gift for Borrowing Books", "Awarded Guessing" and "Classification Method Link Game". These activities are active in forms, and can attract the participation of lots of readers, especially "Searching for Wuhan" and "Book Drifting" activities this year. In the activity of "Searching for Wuhan", readers can search library collections containing Wuhan elements in the library as per the book list; in the activity of "Book Drifting", students contribute idle books, paste the activity logo, and change it for favorite books.

Awarded Work Collections. In the recent years, the library has carried out various work collection activities as per various themes. In 2015, among the 178 collected works from all departments of the entire school, the work of one student from the Computing School-Suddenly Arriving at Tibet-Walking won the first prize. In 2016, the library released the awarded work collection activity of "Searching for Yuyuan Good Text", and through preliminary hearing, WeChat voting, expert review and 
other links, totally 13 people were awarded with the first, second, third prize and the excellence award; "Drunken Tongji" Bookmark Design Competition released by Medical Library Branch totally had 9 people winning the award. Besides, the library has opened a reading pavilion, and readers can read their own awarded works, and select their favorite texts for the reading competition.

Film and Television Exhibitions and Lectures on Humanities. In 2015 World Reading Day activities, the film and television hall played large-scaled documentaryWhen the Louvre Meets the Forbidden City discussing about the cultural communication and integration between the east and the west for 3 continuous days; in 2016, "literature and film in love" photo exhibition was continued to April 23 from April 13, ant totally 6 wonderful films, including War and Peace, Jane Eyre, and Wuthering Heights. Humanistic lectures mainly invited thousands of young people and professors to the library to share reading experience, and this is the important programs during the night of each World Reading Day.

The World Reading Day activity has comprehensively showed "one good book, accompanying you along the way" reading promotion brand of our library, and it is one of the highlights for the brand series of activities. Besides, "a good book, accompanying you along the way" reading promotion brand has also released relevant series of activities for the graduation season, welcoming season and other time nodes.

\section{B. Promote the service of " the library paying for the new books selected by readers"}

The source of reading is books, and in order to better conduct reading promotion, the most essential approach is to firstly select good books, truly sell the books required by readers, and truly give readers their required books, so that reading promotion can promote books, and have a definite object in view.

One of the difficulties bothering the book and reference construction work in colleges is the disjunction of readers' actual demands and book acquisition, so our library takes demands as the orientation, innovates service contents, and firstly releases the new type service of "the libraries paying for the new books selected by readers" among college libraries of the entire province, and readers can select no more than 10 academic books at the Optical Valley Book Store near the school with certificates, including the teaching certificate, working certificate, the student certificate for students registered at school, and then deliver the booklist suggested for purchasing to the specified service counter of the Optical Valley Book Store, and leave the contact information, phone number or e-mail. The booklist selected by readers will be audited by the collecting and editing personnel of the library on line, and then the Optical Valley Book Store will assign special person to send the books confirmed to buy to our library on the current day, and the library will immediately open the book fast processing channel, and complete acceptance, cataloguing, and book reservation within 2 working days, enter into the circulation procedures, and then within 5 working days, the library will inform relevant readers through phone calls or e-mail, to come to the library to handle borrowing procedures.

The new type of service - "the libraries paying for the new books selected by readers" has innovated the book acquisition mode, and prepositioned readers from the service terminal to the interview link, and make readers directly participate in the reference resource construction of libraries, and meanwhile, give the book selection right to readers, make readers enjoy the joy of "private customization" and "zero waiting" service, and has met the individualized reading demands of readers, truly realized "my library, my rules", and this has obtained enthusiastic participation and praises of teachers and students.

\section{Carry out subject librarian book review activities}

Currently, most college libraries have carried out subject service, and set the post of subject librarian. As the bridge for the exchange and communication of teachers and students in colleges, the subject librarian can have a big advantage in reading promotion. Except for daily promoting various resources and services of the library, our library has also carried out subject librarian book review activities, which can also be said as an attempt for subject librarian to participate in reading promotion.

Professor Xu Yan, the President of China Reading Research Institute held that, currently, it was focusing on campus reading promotion, and the emphasis should be conducting well subject librarian book review; the source of books should be selected from Wen Jin Book Award, Tao Feng Book Award, Mao Dun Literature Awards, Nobel Prize in Literature, and other award-winning books; meanwhile, it is also requested to extensively collect the booklist recommended by college presidents, to conduct well the campus reading promotion work [5]. For this reason, the library of our school has released the subject librarian book review activity. We takes Chaoxing Xuexitong as the platform, with the participation of all subject librarians in establishing "the Subject Librarian Book Review Group for the Huazhong University of Science and Technology Library", and all subject librarians will write book review for their recently read books and publish it to the book review group for recommendation and sharing. For instance, among the recently published book reviews, there are Mister Lv's Spring and Autumn Annals, the Literary Minds and the Carving of Dragons, Gone with the Wind, the Essays of Bacon, Une Brève Histoire de L'avenir, and National Geography, and the reviewed books contain extensive contents range from literature and politics to geography and history, and even children reading materials, including When I Feel Worried and the Hundred Dresses. These book reviews won't go with the tide on the internet, but the true feelings of each 
subject librarian; we can push it to the teachers and students of Xuexitong platform.

The value of subject librarian book review not only relies on reading promotion, but also can be said as an important approach for improving the quality of subject librarian. Through the subject librarian book review, it can promote the subject librarian to spend time reading and thinking, and then better conduct reading promotion considering teachers and students, and make the subject librarian itself become the reading participator, and truly realize nationwide reading. Of course, the subject librarian book review activity of our library has just started, and the influence generated in reading promotion is limited, and how to continuously and validly hold the subject librarian book review activity, and how to use subject librarian book review to conduct more valid reading promotion are problems that should be further discussed.

\section{Adhere to holiday reading promotion}

How to guide students to use holidays to validly read is also an important task for college libraries. The holiday reading promotion of library in our school is mainly carried out for teachers and students inside and outside the school.

Specific to the reading promotion carried out for teachers and students outside the school, it can be specifically divided into the implementation during three time periods, including before the winter vocation, during the holiday, and after the beginning of the term. Before the holiday, the working personnel of the library have recommended or collected some excellent book information, fabricated "the holiday recommended reading books" publicity display panel, and then synchronously play it on the home page of the library and the electronic screen inside the library, to carry forward the positive energy of advocating learning and reading, self-cultivation and patriotism; during the holiday, in order to enhance the connection between the library and the readers, facilitate readers to timely acquire various series of the library, the library has released the roaming interview service of electronic reference resources during holidays, and then provide borrowing guidance to readers through WeChat public platform of the library; after the beginning of the term, in order to reinforce the reading effect during holidays, the library has focused on the recommended booklists to carry out rich and colorful reading interaction activities with vast readers, so as to better master the reading conditions of readers during holiday and the promotion effect of recommended booklists.

We not only use the library to carry out promotion service for teachers and students outside the school during holidays, but also use the library to provide many conveniences for teachers and students at school. For instance, during holidays, overseas students mostly choose to study at the library, and the quantity of students entering into the library will be increased, and there will be the phenomenon of lots of students waiting in line before the library every morning. Regarding this, the library has timely adopted corresponding service measures. In order to solve problems such as the demand exceeding supply in the reading room, the library has adjusted the opening arrangement during the summer holiday, and increased the opening seats; in order to solve the problem of students getting up early and waiting for entrance under high temperature, the opening time for $1 \mathrm{~F}$ hall of the new library has been changed to 7:00am From 8:30am per day; in order to solve the problem of students lining up crowdedly during the opening, the library has adjusted the seas booking system, encouraged students to book seats in advance, to decrease the time to line up, and the booking quantity for the current seat has exceeded $95 \%$.

\section{E. Make a full play of the promotion function of the reading club}

The reading club for the library of our school was established in 2009 , and as a platform erected by the library for the ideological and cultural exchange with students, the reading club is the bridge between the library and students; it can exert an active effect in developing and utilizing the library references and resources, to transmit excellent culture, form a good atmosphere for reading enthusiasm, and promoting the construction of campus culture, especially in reading promotion, the reading club has made a lots of endeavors, and released various forms of reading promotion activities.

Editing and Issuing Holiday Reading Booklists. The reading club of the library has adhered to implementing scientific theories arming the people, correct opinions guiding the people, noble spirits building the people, excellent work encouraging the people, and the holiday reading booklists mostly use the excellent books of "Five One Project", the winning works of Mao Dun Literature Awards, the winning works of Lu Xun Literary Prize, etc. as the references, and then they are formed in combination with the actual editing of college students, and the members will be provided with reading booklists during each holiday.

Creating Reading Communication Space. The reading club has created an open reading communication community inside the library, and gathered rich learning resources, and can provide ten people and above communication discussion, facilitate student community, student scientific research team, entrepreneurship team and even students of the same dormitory to communicate at the library.

Actively carrying out "respecting excellent traditional Chinese culture" activities. In order to respond to "reading traditional classics, and experiencing the life of literary families - respecting excellent traditional Chinese culture" theme activity, the reading club has successively participated in holding "excellent traditional culture themed exhibition", "excellent traditional culturejoint discussion about traditional holidays-Dragon Boat Festival" exhibition, and carried out "carrying forward 
traditional culture, and speaking glowingly of Chinese time-honored brand" reading sharing conference.

Besides, the reading club has also held reading into students' community-living library activity, organized students to experience "the libraries paying for the new books selected by readers", periodically organize members to carry out special learning discussion, etc., and made lots of attempts in reading promotion. In these years, the achievements of the reading club have obtained many affirmations inside and outside the school. On June 6, 2011, China Education Daily recommended the Reading Club of Huazhong University of Science and Technology under the title of "reading club: a big family for students to grow fast". In 2012, the reading club of the library won the title of Youxin China Colleges Best Community. In 2014, Hubei Provincial Nationwide Reading Leading Group was selected as the Top Ten Best Young Literary Family Number in Hubei Province in 2013, and then in the same year, the reading club of the library won the Second Prize of China Society for Library Science Reading Promotion Committee for national excellent cases.

\section{CONCLUSIONS}

Library is a growing organism, and reading promotion is not the work of certain specific business department, or something that can be completed in one day; it should be a continuous process, and the service activity that can be participated by all departments of the library. From reference purchasing to book circulation and from reference consulting to subject service, all college libraries may have different divisions in organizational structure, but reading promotion shouldn't have strict business division, and it is the responsibility for all librarians in all departments of the entire library.

\section{REFERENCES}

[1] Wu Gao, Wei Nanhua. Existing Problems and Countermeasures about the Reading Promotion of College Libraries in Our Country [J]; Library and Information Service, 2013, 57(3): 47-51.

[2] Xu Tiancai, Yang Xinya, Xu Juan et al. Research about the Reading Promotion Evaluation Mechanism of College Libraries [J]; Library and Information Service, 2016, 60 (17): 47-52.

[3] Li Yuanyuan. Research about the Reading Promotion Mechanism of College Libraries-Taking the Vertical Reading of the Library of Tongji University as an Example [J]; Researches in Library Science, 2014, (07): 85-88+96.

[4] Lei Juxia, Qiao Jing, and Yuan Yumin. Discussion about the Reading Promotion Work of Libraries under the New Environment- the Practice and Reflections about the Reading Promotion of Beijing Normal University [J]; Journal of Academic Libraries, 2014, 32 (05): 86-91.

[5] Xu Yan. Reading, Walking along with Classics - Selection of Reading Materials and the Pursuit of Happiness [Z]. Report about the Seminar of Reading Promotion for College Libraries in Northeast China Rregion, 2016. 